\title{
Characterisation of soiled water on Irish dairy farms
}

D Minogue $^{1,2}$, P Murphy ${ }^{1}$, P French $^{1}$, F Coughlan $^{1}$, T Bolger ${ }^{2}$

${ }^{1}$ Teagasc, Moorepark Dairy Production Research Centre, Cork, Ireland

${ }^{2}$ School of Agriculture, Food Science \& Veterinary UCD, Dublin, Ireland

Introduction Soiled water on dairy farms consisting mainly of parlour wash water and run-off from soiled yard areas and contains nutrients that are potentially plant-available but may also pose a risk of environmental pollution if not managed correctly. Effective management of soiled water may lead to cost savings in fertiliser use and address environmental concerns as legislated in the EU Nitrates Directive and Water Framework Directive. Knowledge of the volumes, contents and management practices on Irish farms is a first step towards effective management, but there is very little information on this to-date. The objective of this study was to characterise soiled water and soiled water management practices on Irish dairy farms.

Material and methods Sixty dairy farms were selected with a geographic distribution reflecting that of the national dairy herd. Farm selection was constrained by the requirement that all soiled water was collected in a single tank and that there were no other inputs to this tank. Farms were visited every 28 days for one year, commencing in April 2008, giving13 sample dates per farm. A $500 \mathrm{ml}$ sample was taken from below the surface crust and analysed for total $\mathrm{N}(\mathrm{TN}), \mathrm{NH}-\mathrm{N}_{4}$, Total Oxidisable N, K, molybdate reactive P, Total P (TP), Biochemical Oxygen Demand (BOD) and dry matter (DM). Soiled water volumes were recorded by logging vacuum tanker loads or by flow meters on farms using a pumped irrigator system. Farm descriptions and management characteristics were recorded also. Descriptive statistics were used to characterise soiled water quantities and composition.

Table 1 Mean soiled water concentrations (mg/l) and annual production $(\mathrm{kg})$.

\begin{tabular}{llll}
\hline \hline Nutrient & $\begin{array}{l}\text { Mean } \\
\text { concentration } \\
(\mathrm{mg} / \mathrm{l})\end{array}$ & s.d. & $\begin{array}{l}\text { Annual production } \\
\mathrm{kg} / \text { cow/year (s.d) }\end{array}$ \\
\hline $\mathrm{TN}$ & 587 & 536 & $6.0(3.96)$ \\
$\mathrm{NH}_{4}-\mathrm{N}$ & 212 & 206 & $2.2(1.2)$ \\
$\mathrm{K}$ & 568 & 513 & $5.7(3.0)$ \\
$\mathrm{TP}$ & 80 & 68 & $0.8(0.5)$ \\
$\mathrm{DM}$ & 5000 & 5200 & $97841(5135)$ \\
$\mathrm{BOD}$ & 2246 & 2112 & \\
\hline \hline
\end{tabular}

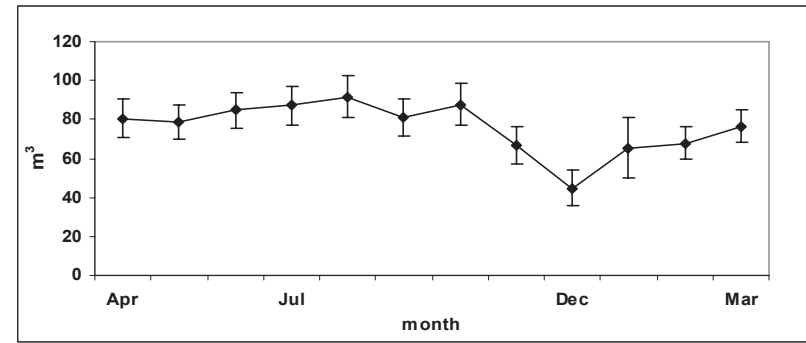

Figure 1 Mean soiled water production (and standard errors)

Table 2 Farm description and management details

\begin{tabular}{lllll}
\hline \hline Description & Mean & s.d & Description & $\%$ \\
\hline farm size & $74 \mathrm{ha}$ & $31 \mathrm{ha}$ & spring calving & 74 \\
herd size & 102 & 92 & roofed collection yard & 31 \\
\# milking units & 12 & 7 & single stage storage & 90 \\
area washed & $98.35 \mathrm{~m}^{2}$ & $77.34 \mathrm{~m}^{2}$ & other effluents mixed & 17 \\
tank size & $66 \mathrm{~m}^{3}$ & $42 \mathrm{~m}^{3}$ & vacuum tanker & 81 \\
\hline \hline
\end{tabular}

Results and Discussion Eighty one percent of farms used a vacuum tanker to spread soiled water while the remainder used an irrigation system. Average annual volume produced was $916 \mathrm{~m}^{3}$ (SD, 723). Mean tank storage capacity for soiled water was 33 days (SD, 23) and $94 \%$ of farms had at least the legally required storage capacity of 10 days. As mean tank size was $66 \mathrm{~m}^{3}(\mathrm{SD}, 42)$ there is limited capacity to store soiled water for long periods. This presents a challenge for nutrient management as soiled water cannot generally be stored until optimal application times. Production varied over the year with a winter minimum (Fig. 1), likely due to the decrease in cows milking in this period (74\% of farms were spring calving) (Table 2). This minimum coincides with the period of highest risk of nitrate leaching from land application and likely decreases the risk of nutrient loss from soiled water. Seventy three percent of samples were below the legal definition of soiled water for BOD $(2500 \mathrm{mg} / \mathrm{l})$. This further increased to $86 \%$ during the winter period, most likely due to the decrease in cows milking, tanks becoming unused and stagnant and increased dilution from rainfall. Mean $\mathrm{N}$, $\mathrm{P}$ and $\mathrm{K}$ concentrations were 587,80 and $568 \mathrm{mg} / \mathrm{l}$, respectively. $\mathrm{NH}_{4}-\mathrm{N}$ concentration was $212 \mathrm{mg} / \mathrm{l}$, the balance consisting mostly of plant-unavailable organic N. Therefore, roughly a third of TN consists of rapidly plant-available $\mathrm{NH}_{4}-\mathrm{N}$. Although nutrient concentrations are low, in comparison to slurry, the large volumes produced offer a potentially significant nutrient source, particularly given evidence for increased $\mathrm{N}$ availability at lower DM content. On average, 97841 of soiled water were produced per cow per year, supplying $6.0 \mathrm{~kg} \mathrm{~N}, 5.7 \mathrm{~kg} \mathrm{~K}$ and $0.8 \mathrm{~kg}$ P. Nutrient quantities and concentrations vary widely and this presents a challenge for effective nutrient management.

\section{Conclusions}

Production had a winter minimum coinciding with the period of highest risk of nitrate leaching from land application. Although nutrient concentrations are low in comparison to slurry, soiled water contains significant $\mathrm{N}, \mathrm{K}$ and $\mathrm{P}$.

Nutrient quantities and concentrations varied widely and this presents a challenge for effective nutrient management.

Acknowledgements This Study was funded by the Department of Agriculture, Fisheries and Food Research Stimulus Fund. 